\title{
A sex-specific role for androgens in angiogenesis
}

\author{
Daniel P. Sieveking, ${ }^{1,2}$ Patrick Lim,${ }^{1}$ Renée W.Y. Chow, ${ }^{1}$ Louise L. Dunn, ${ }^{1}$ \\ Shisan Bao, ${ }^{3}$ Kristine C.Y. McGrath, ${ }^{1}$ Alison K. Heather, ${ }^{1}$ \\ David J. Handelsman, ${ }^{4,5}$ David S. Celermajer, ${ }^{1,2,6}$ and Martin K.C. Ng ${ }^{1,2,6}$
}

${ }^{1}$ Heart Research Institute, Sydney 2042, Australia

${ }^{2}$ Department of Medicine and ${ }^{3}$ Department of Pathology, University of Sydney, Sydney 2050, Australia ${ }^{4}$ ANZAC Research Institute, Sydney 2139, Australia

5Department of Andrology, Concord Hospital, Sydney 2139, Australia

${ }^{6}$ Department of Cardiology, Royal Prince Alfred Hospital, Sydney 2050, Australia

\begin{abstract}
Mounting evidence suggests that in men, serum levels of testosterone are negatively correlated to cardiovascular and all-cause mortality. We studied the role of androgens in angiogenesis, a process critical in cardiovascular repair/regeneration, in males and females. Androgen exposure augmented key angiogenic events in vitro. Strikingly, this occurred in male but not female endothelial cells (ECs). Androgen receptor (AR) antagonism or gene knockdown abrogated these effects in male ECs. Overexpression of AR in female ECs conferred androgen sensitivity with respect to angiogenesis. In vivo, castration dramatically reduced neovascularization of Matrigel plugs. Androgen treatment fully reversed this effect in male mice but had no effect in female mice. Furthermore, orchidectomy impaired bloodflow recovery from hindlimb ischemia, a finding rescued by androgen treatment. Our findings suggest that endogenous androgens modulate angiogenesis in a sex-dependent manner, with implications for the role of androgen replacement in men.
\end{abstract}

\section{CORRESPONDENCE \\ Martin K.C. Ng: \\ mkcng@med.usyd.edu.au \\ OR \\ Daniel P. Sieveking: \\ sievekingd@hri.org.au}

Abbreviations used: AcLDL, Dil-acetylated low density

lipoprotein; ANOVA, analysis of variance; AR, androgen receptor; $\mathrm{CVD}$, cardiovascular disease; DHT, dihydrotestosterone; EC, endothelial cell; ER, estrogen receptor; HF, hydroxyflutamide; HIF-1, hypoxia-inducible factor 1 ; LDPI, laser Doppler perfusion index; MNC, mononuclear cell; mRNA, messenger RNA; PI3K, phosphoinositol 3-kinase; SDF-1 $\alpha$, stromal cell-derived factor $1 \alpha$; siRNA, small interfering RNA; VEGF, vascular endothelial growth factor; vWF, von Willebrand factor.
The role of androgens in cardiovascular disease (CVD) remains controversial. Although men develop CVD earlier than women, consistent with increased atherosclerosis (Wingard et al., 1983; Shaw et al., 2006), repair/adaptation mechanisms may be enhanced in males (Joseph and Dyson, 1965). For example, male sex is associated with increased collateralization in patients with severe coronary artery lesions (Abaci et al., 1999). Androgens have been implicated in playing a detrimental role in CVD by numerous in vitro studies (McCrohon et al., 1999; Ng et al., 2003a,b), but in vivo and clinical studies fail to support this relationship (Liu et al., 2003; Wu and von Eckardstein, 2003; Harman, 2005). Indeed, some but not all cohort studies suggest that subnormal blood levels of testosterone are deleterious and correlate with increased cardiovascular risk factors and mortality (Araujo et al., 2007; Khaw et al., 2007; Laughlin et al., 2008; Tivesten et al., 2009).

Angiogenesis is a prerequisite for embryonic development and plays a critical role in adult physiological processes such as wound repair and in tissue responses to ischemia (Carmeliet, 2005). The cardiovascular system is an important target of androgen action (Liu et al., 2003), and although the effect of estrogen in angiogenesis has been studied extensively (Losordo and Isner, 2001), the role of androgens in this process remains largely unexplored.

Androgens have been implicated in the renewal of various tissues, including muscle and bone (Harman, 2005), but their potential role in the maintenance of cardiovascular repair mechanisms is unknown. As androgens have been implicated in the regulation of angiogenesisrelated genes (Ng et al., 2003b; Death et al., 2004), we reasoned that androgens may play a role in angiogenesis, a process critical in the regenerative response after ischemia. To examine the role of androgens in angiogenesis, we used dihydrotestosterone (DHT), the most potent natural androgen that acts via the androgen receptor (AR). As testosterone action partly depends on its conversion to estradiol by the unique enzyme CYP19 (aromatase), whereas

\footnotetext{
2010 Sieveking et al. This article is distributed under the terms of an Attribution-Noncommercial-Share Alike-No Mirror Sites license for the first six months tion-Noncommercial-Share Alike-No Mirror Sites license for the first six months
after the publication date (see http://www.jem.org/misc/terms.shtml). After six months it is available under a Creative Commons License (Attribution-Noncommercial-Share Alike 3.0 Unported license, as described at http://creativecommons .org/licenses/by-nc-sa/3.0/).
} 
DHT cannot be aromatized, the use of DHT avoids the potentially confounding estrogen receptor (ER)-mediated effects of testosterone.

\section{RESULTS AND DISCUSSION}

Androgens augment angiogenic events in vitro in male endothelial cells (ECs)

Male ECs treated with DHT demonstrated a dose-dependent increase in key angiogenic processes in vitro (Fig. 1). EC migration was assessed by two different methods. Cells were pretreated with varying doses of DHT (0, 4, 40, and $400 \mathrm{nM})$ and subsequently assessed using a Boyden chamber assay or a scratch wounding assay. Using the Boyden chamber assay, $24 \mathrm{~h}$ of DHT administration induced dose-dependent male EC migration $(220 \pm 22,262 \pm 38$, and $336 \pm 39 \%$ vs. $100 \%$ control value for DHT at 4, 40, and $400 \mathrm{nM}$, respectively; $\mathrm{P}<$ 0.001 using analysis of variance [ANOVA]; Fig. 1 B). Similar results were obtained using a scratch wounding assay. Migration by male ECs was augmented in a dose-dependent fashion $(138 \pm 7,280 \pm 23$, and $306 \pm 32 \% ; \mathrm{P}<0.01$ using ANOVA; Fig. $1 \mathrm{C}$ ). Interestingly, in both assays, addition of the AR antagonist hydroxyflutamide (HF) abrogated DHT-mediated EC migration $(96 \pm 6$ and $94 \pm 6 \%$ vs. $100 \%$ control value for 40 and $400 \mathrm{nM} \mathrm{DHT}+\mathrm{HF}$, respectively; P > 0.05; Fig. 1, $\mathrm{B}$ and $\mathrm{C})$. DHT effects on tubulogenesis were assessed using both Matrigel and co-culture methods (Sieveking et al., 2008).
Chronic exposure to DHT (72 h) induced a dose-dependent increase in male EC tubulogenesis (Fig. 1, D and E), as did $24 \mathrm{~h}$ of exposure (Fig. S1). Similarly, DHT augmented male EC proliferation in a dose-dependent fashion after $48 \mathrm{~h}$ (Fig. $1 \mathrm{~F}$ ). Again, addition of HF abolished all androgen-mediated effects on these key angiogenic events, consistent with an ARdependent mechanism (Fig. 1, B, C, E, and F).

As an independent method to verify the pivotal involvement of AR in DHT-mediated angiogenic effects, we also assessed tubulogenesis in male ECs subjected to small interfering RNA (siRNA)-mediated knockdown of AR. DHT effects were also abolished in ECs exposed to AR siRNA (Fig. $1 \mathrm{G})$. DHT can also mediate effects via direct cross-reactivity at the ER at sufficiently high concentrations. Therefore, to further exclude any contribution to DHT effects via effects on ERs, we assessed tubulogenesis in male ECs treated with the highest concentration of DHT with or without the ER antagonist ICI182780. The addition of ICI182780 did not have any effect on DHT-mediated augmentation of tubulogenesis (Fig. $1 \mathrm{H}$ ). These findings are consistent with an ARmediated angiogenic effect in male ECs.

\section{Androgens do not augment angiogenic events in vitro in female ECs}

Mounting evidence indicates that sex steroids regulate various vascular biological processes in a sex-dependent fashion
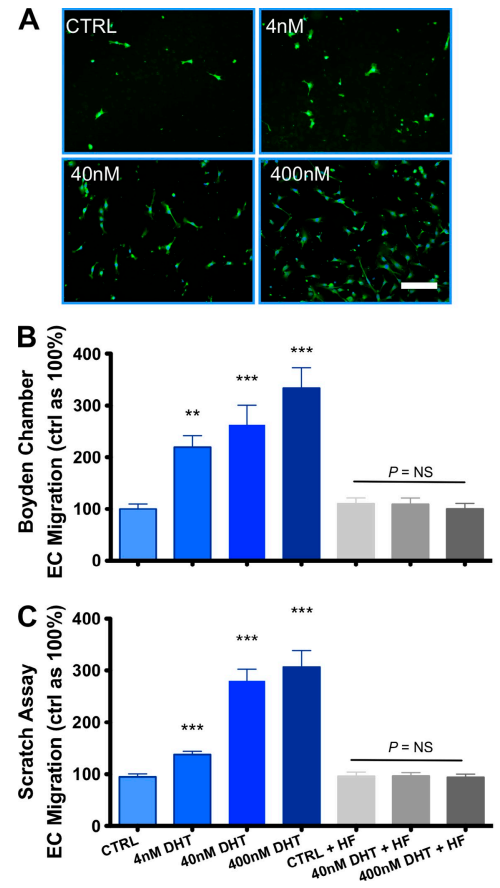
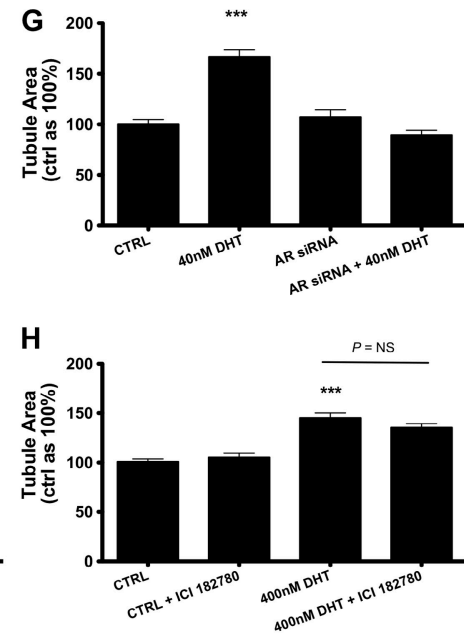

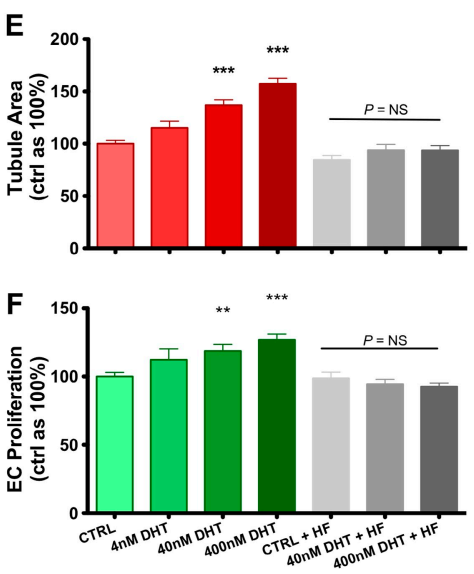

Figure 1. DHT augments key angiogenic events in vitro in male ECs via the AR. (A and B) Boyden chamber (cells were stained with Ulex lectin [UEA-1] and DAPI) and (C) scratch wounding assays of migration by male ECs pretreated with DHT or vehicle (0.1\% EtOH) for $24 \mathrm{~h} \pm \mathrm{HF}$, assessed after 6 and $24 \mathrm{~h}$, respectively. Bar, $50 \mu \mathrm{m}$. (D and E) Vascular network formation by male ECs exposed to DHT or vehicle \pm HF for $72 \mathrm{~h}$. Tubule area was quantified using image analysis software (ImageJ; available at http://rsbweb.nih.gov/ij/). Bar, $100 \mu \mathrm{m}$. (F) Proliferation of male ECs exposed to DHT or vehicle \pm HF for $24 \mathrm{~h}$, assessed by direct cell counting ( $n=4$ independent experiments for A-F, respectively). ( $G$ and $H$ ) Matrigel assays of male ECs transfected with siRNA targeted to the AR $(G)$ or pretreated with the ER blocker ICl182780 and treated with $\mathrm{DHT}\left(\mathrm{H} ; n=3\right.$ independent experiments). ${ }^{*}, \mathrm{P}<0.01 ;$ and ${ }^{* * *}, \mathrm{P}<$ 0.001 versus control using ANOVA. All data are expressed as means \pm SEM. For each independent experiment, cells from a different donor were used. 
(McCrohon et al., 1999; Ng et al., 2001; Ng et al., 2003b). For androgens, this is related to an approximately two- to fourfold increased AR expression in male vascular cells compared with females (McCrohon et al., 2000; Death et al., 2004). We therefore hypothesized that the proangiogenic effects of DHT observed in ECs may also be sex dependent. Unlike male ECs, exposure of female ECs to DHT had no effect on migration (Fig. 2, A and B), tubulogenesis (Fig. 2 C), or proliferation $(\mathrm{P}>0.05$; Fig. $2 \mathrm{D})$, consistent with androgen-mediated sex-specific effects. To further examine the role of the AR in mediating the sex-dependent effects of DHT on angiogenesis, we overexpressed the AR in female ECs (Fig. S2) and assessed tubulogenesis after exposure to DHT. Female ECs overexpressing the AR became responsive to DHT and displayed augmented tubulogenesis (114 \pm $6 \%$ vs. $100 \%$ control value; $\mathrm{P}<0.05$ using the Student's $t$ test), albeit to a lesser extent than in male cells (Fig. 2 E). These findings indicate that the sex-specific effects of DHT on angiogenesis are at least in part mediated by sex differences in AR expression. As there are a variety of coregulators involved in AR signaling (Liu et al., 2003), it is also possible that many of these are also expressed in a sex-specific fashion and are important for androgenic modulation of angiogenesis.

\section{The proangiogenic effect of androgens in vitro are vascular} endothelial growth factor (VEGF) dependent

Next, to further elucidate the means by which DHT augmented migration, proliferation, and tubulogenesis in male ECs, cells exposed to DHT were assessed for the expression of various proangiogenic factors. Exposure of male ECs to DHT produced a dose-dependent increase in the production of VEGF, a key angiogenic growth factor $(102.8 \pm 7,107.8 \pm 7$, $118.9 \pm 6$, and $147.2 \pm 15 \mathrm{pgVEGF} / 100 \mu \mathrm{g}$ of cell protein for $0,4,40$, and $400 \mathrm{nM}$ DHT, respectively; $\mathrm{P}=0.0024$; Fig. 3 A). Similarly, DHT induced dose-dependent increases in the messenger RNA (mRNA) expression of VEGF receptors 1 and 2 (Flt-1 and KDR, respectively; Fig. 3, B and C). However, flow cytometric assessment of surface VEGF receptor levels revealed that DHT augmented KDR but not Flt-1 expression in a dose-dependent manner (Fig. 3, D and E). As $\mathrm{KDR}$ is the chief mediator of the mitogenic/angiogenic action of VEGF in ECs, whereas Flt-1 may function as a negative regulator of VEGF action (Ferrara et al., 2003), our findings are consistent with a proangiogenic role for DHT through VEGF signaling via KDR. Furthermore, the addition of antiVEGF antibody abrogated DHT-mediated increases in tubulogenesis (Fig. 3 F). Likewise, LY294002, an inhibitor of phosphoinositol 3-kinase (PI3K), a key enzyme in the PI3KAKT pathway of VEGF signaling, inhibited DHT-mediated tubulogenesis (Fig. 3 F). These findings suggest that the proangiogenic effects of DHT in male ECs are VEGF dependent.

\section{Endogenous androgens are necessary for angiogenesis in vivo in males but not females}

Having demonstrated a sex-specific role for androgens in angiogenesis in vitro, we next assessed the role of androgens in angiogenesis in vivo, first using a Matrigel plug implantation model. Sexually mature male and female mice underwent gonadectomy or a sham gonadectomy followed by DHT administration. Orchidectomy markedly decreased in vivo vascularization of Matrigel plugs $\left(27.3 \pm 2 \% \mathrm{~mm}^{2}\right.$ von Willebrand factor $[\mathrm{vWF}]^{+}$cells $/ \mathrm{mm}^{2}$ Matrigel vs. control as 100\%; P < 0.0001 using ANOVA; Fig. 4 A). As can be observed in the representative image, these plugs were virtually acellular. Androgen treatment fully reversed the castration-related impairment of angiogenesis in males, returning
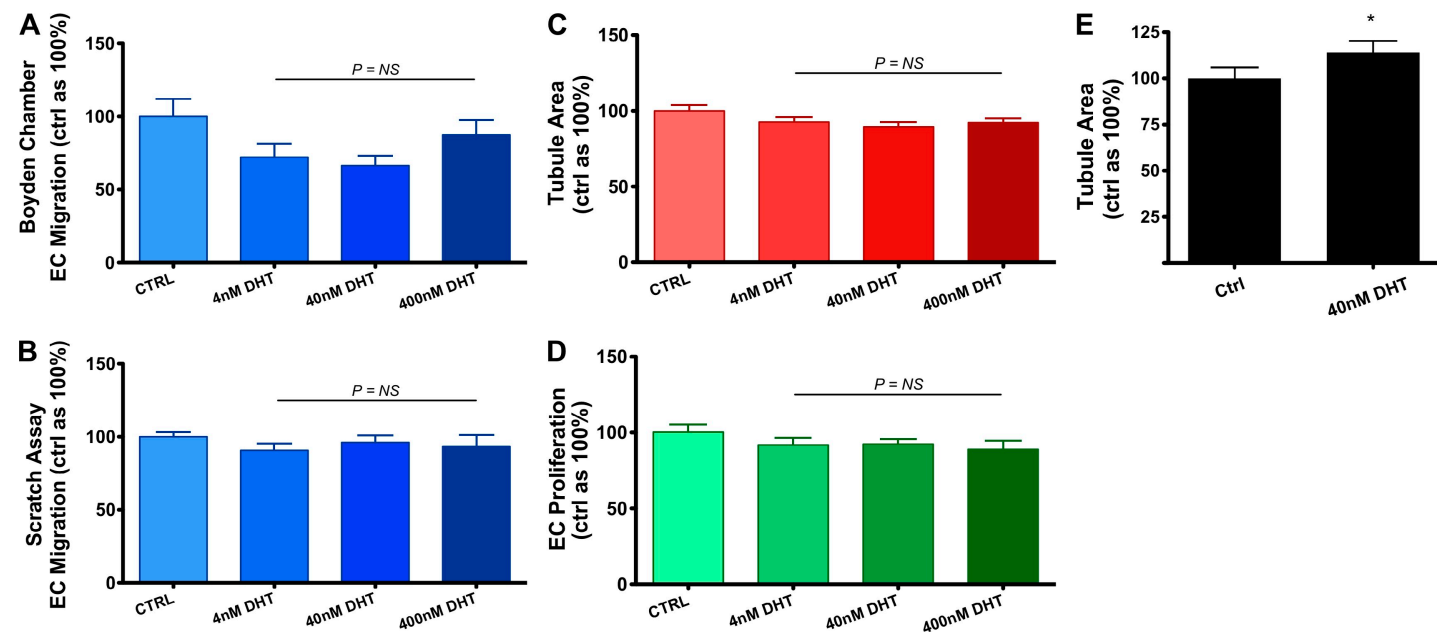

Figure 2. DHT does not augment key angiogenic events in vitro in female ECs. (A-D) Boyden chamber (A) and scratch wounding (B) assays of migration assessed after 6 and $24 \mathrm{~h}$, respectively, Matrigel assays (C), and proliferation by female ECs treated with DHT or vehicle (D; $n=4$ independent experiments). $\mathrm{P}>0.05$ using ANOVA. (E) Matrigel assays of female ECs transfected with an AR overexpression plasmid and treated with DHT $(n=$ 3 independent experiments). ${ }^{*}, \mathrm{P}<0.05$ using the Student's $t$ test. All data are expressed as means \pm SEM. For each independent experiment, cells from a different donor were used. 
vascularization of Matrigel plugs to levels not significantly different to controls $\left(91 \pm 6 \% \mathrm{~mm}^{2} \mathrm{vWF}^{+}\right.$cells $/ \mathrm{mm}^{2}$ Matrigel vs. control as 100\%; $\mathrm{P}<0.001)$.

Consistent with previous findings, ovariectomy attenuated Matrigel plug vascularization in females (Morales et al., 1995), albeit to levels more modest than in males $\left(53 \pm 8 \% \mathrm{~mm}^{2}\right.$ $\mathrm{vWF}^{+}$cells $/ \mathrm{mm}^{2}$ Matrigel vs. control as $100 \%$; $\mathrm{P}<0.0001$ using ANOVA; Fig. 4 B). In striking contrast to their male counterparts, gonadectomy-related impairment of angiogenesis in females was not reversed by DHT treatment ( $55 \pm 6 \%$ vs. control as $100 \% ; \mathrm{P}<0.0001$ using ANOVA). In accordance with our in vitro findings, these data suggest that endogenous androgens play a role in angiogenesis in males but not females.

\section{Endogenous androgens modulate ischemia-induced angiogenesis}

Hypoxia is one of the most potent angiogenic stimuli (Ceradini and Gurtner, 2005). To investigate the role of androgens in ischemia-induced angiogenesis, we used a mouse model of hindlimb ischemia involving the unilateral ligation and removal of the femoral artery (Couffinhal et al., 1998). Male mice were randomized to orchidectomy with or without DHT treatment or a sham orchidectomy. Laser Doppler perfusion imaging demonstrated that orchidectomy markedly inhibited the rate of recovery from hindlimb ischemia (laser Doppler perfusion index [LDPI] ischemic/nonischemic ratio after $11 \mathrm{~d}$ : control, $0.54 \pm 0.04$; castrate, $0.39 \pm 0.04 ; \mathrm{P}<$ 0.05; Fig. $5 \mathrm{~A}$ ). In functional assessments of the ischemic hindlimbs, orchidectomized animals also displayed impaired recovery in foot movement and ischemic damage (Fig. S3). Interestingly, DHT not only rescued the orchidectomyinduced impairment of blood flow recovery but also enhanced recovery from ischemia, with improvements in flow detectable as early as day 3 and significant by day 5 after ischemia (LDPI at day 5 after ischemia: control, $0.28 \pm 0.04$; orchidectomized + DHT, $0.4 \pm 0.05 ; \mathrm{P}<0.05$ vs. orchidectomized mice; Fig. 5 A). These findings were also borne out in the functional assessments of recovery (Fig. S3). The serial changes in perfusion observed after femoral artery ligation have previously been shown to correlate with changes in vessel density as determined by histological analysis (Couffinhal et al., 1998). As early as day 7 , immunohistochemical staining of the adductor muscles of the ischemic hindlimbs revealed that capillary density was impaired in orchidectomized mice and augmented in DHT-treated orchidectomized mice $(0.17 \pm$ 0.01 and $0.27 \pm 0.01$ vs. $0.22 \pm 0.01$ capillaries/myofiber for orchidectomized mice, orchidectomized + DHT mice, and controls, respectively; $\mathrm{P}<0.001$ using ANOVA; Fig. 5, B and $\mathrm{C}$ ), consistent with the findings observed for limb perfusion. Mean vessel diameter was also significantly smaller in orchidectomized mice $(\mathrm{P}<0.001$; Fig. 5 D). Interestingly, mean vessel diameter was also smaller in orchidectomized mice receiving DHT, but DHT treatment appeared to mitigate the effects of castration. These data suggest that, in the context of ischemia, endogenous androgens influence the rate and extent of ischemia-induced angiogenesis and play a role in arteriogenesis.

To elucidate the mechanisms of androgen-induced angiogenesis in the context of hindlimb ischemia, we assessed the early expression of angiogenesis- and ischemia-related genes. Notably, 3 d after ischemia, orchidectomy significantly reduced the expression of hypoxia-inducible factor $1 \alpha(\mathrm{HIF}-1 \alpha$ $0.5 \pm 0.1$ vs. $1.8 \pm 0.2$ relative mRNA expression ischemic/ nonischemic for orchidectomized mice vs. controls, respectively; $\mathrm{P}<0.05$ using ANOVA) and stromal cell-derived factor $1 \alpha(\mathrm{SDF}-1 \alpha ; 0.7 \pm 0.1$ vs. $2.4 \pm 0.1$ relative mRNA
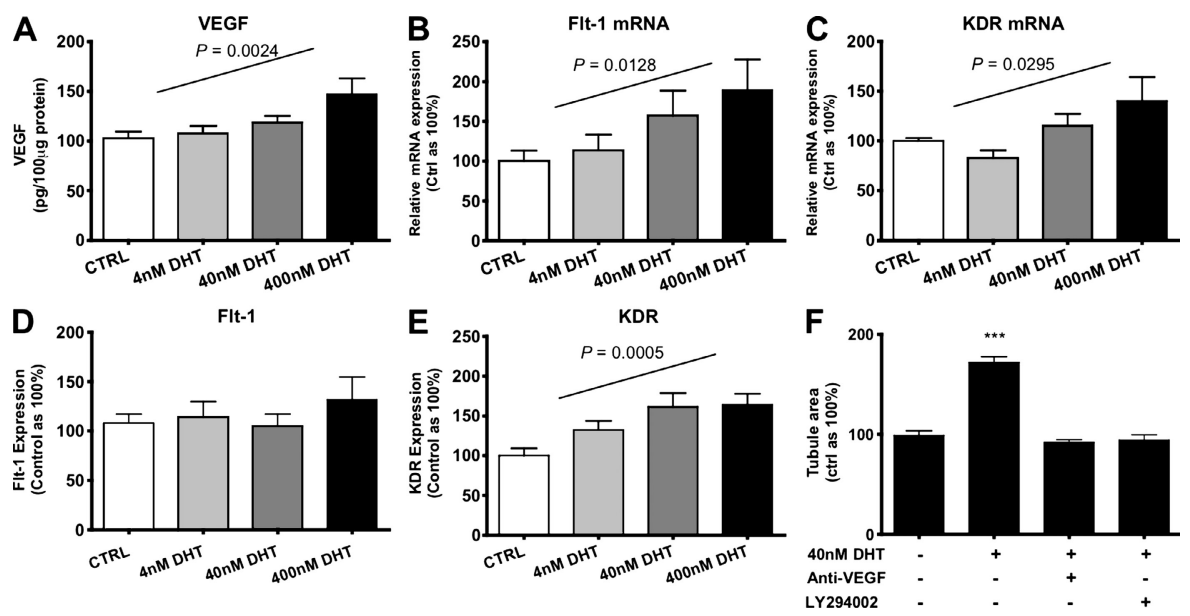

Figure 3. Proangiogenic effects of DHT in male ECs is VEGF dependent. (A) Production of VEGF by male ECs exposed to DHT for $48 \mathrm{~h}$. Total cell lysate protein was quantified and assayed via ELISA ( $n=4$ independent experiments). $\mathrm{P}=0.002$ using ANOVA for linear trend. (B) Expression of FIt- 1 $(P=0.0128)$ and $(C) K D R(P=0.0295)$ mRNA and $(D) F l t-1$ and $(E) K D R(P=0.0005)$ protein in male ECs exposed to DHT for $48 \mathrm{~h}$ (using ANOVA for linear trend). (F) Vascular network formation in male ECs treated with DHT with and without $1 \mu \mathrm{g} / \mathrm{ml}$ anti-VEGF antibody or $10 \mu \mathrm{M}$ of the PI3K inhibitor LY294002 ( $n=3$ independent experiments for B-F, respectively). ${ }^{* * *}, \mathrm{P}<0.001$ compared with control using ANOVA. All data are expressed as means \pm SEM. For each independent experiment, cells from a different donor were used. 
expression ischemic/nonischemic for orchidectomized mice vs. controls, respectively; $\mathrm{P}<0.05$ using ANOVA), which are key factors in the coordination of angiogenic gene expression and progenitor cell migration and homing, respectively (Fig. 5, E and F, respectively; Ceradini et al., 2004). In stark contrast, DHT treatment of orchidectomized mice augmented expression of HIF-1 $\alpha(3 \pm 0.8 ; \mathrm{P}<0.01)$ and SDF-1 $\alpha(3.6 \pm$ $0.9 ; \mathrm{P}<0.01)$. These mice also demonstrated increased expression of KDR ( $3 \pm 0.8$ vs. 0.6 for orchidectomized + DHT vs. controls, respectively; P <0.01 using ANOVA; Fig. 5 G), providing support for a role of DHT in VEGF signaling in vivo. Furthermore, similar trends were observed for VEGF and neuropillin-1 (Fig. S4). HIF-1 $\alpha$ is the key subunit to HIF-1, which is a critical, genome-wide transcription regulator responsible for oxygen homeostasis and responsive to hypoxic stress (Semenza, 2002; Ceradini and Gurtner, 2005). It drives the expression of $>100$ genes, including key genes associated with angiogenesis such as VEGF and its receptors (Semenza, 2002). It is noteworthy that androgens have been associated with HIF-1 expression in the prostate (Boddy et al., 2005). Hence, it is possible that in addition to the direct effects of
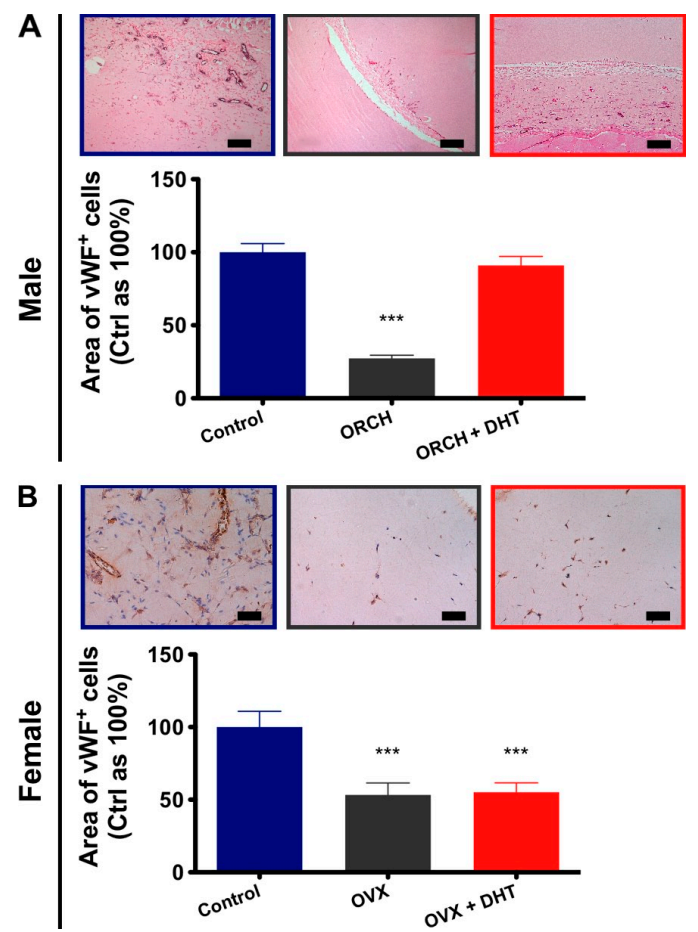

Figure 4. Endogenous androgens play a role in angiogenesis in males but not females. (A) Vascularization of Matrigel plugs harvested from male mice after $14 \mathrm{~d}$, with representative images ( $n=8 / \mathrm{group}$; combined data from four independent experiments are shown). Sections were immunohistochemically stained for VWF (3,3'-diaminobenzidine [DAB] + nickel, eosin). Bars, $100 \mu \mathrm{m}$. (B) Vascularization of Matrigel plugs harvested from female mice, with representative images ( $n=5$-6/group; combined data from three independent experiments are shown). Sections were immunohistochemically stained for vWF (DAB, hematoxylin). Bars, $50 \mu \mathrm{m} .{ }^{* * *}, \mathrm{P}<0.001$ versus control using ANOVA. All data are expressed as means \pm SEM.
DHT, the increases observed for SDF- $1 \alpha$ and KDR in DHTtreated mice are also related to induction of HIF-1 $\alpha$ (Ceradini et al., 2004). There were trends toward a reduction in VEGF expression in orchidectomized animals and an increase with DHT treatment that were not statistically significant. Nevertheless, given the critical role of HIF-1 $\alpha$ in inducing VEGFrelated angiogenic events in ischemia and an increased expression of $\mathrm{KDR}$, our in vivo findings are compatible with a role for

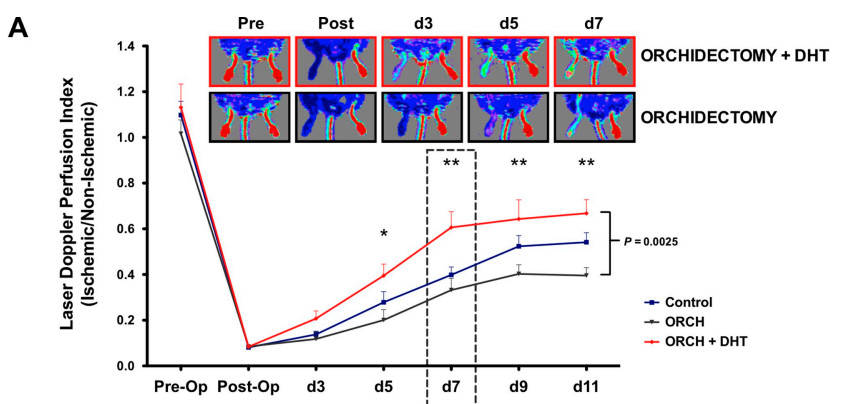

B
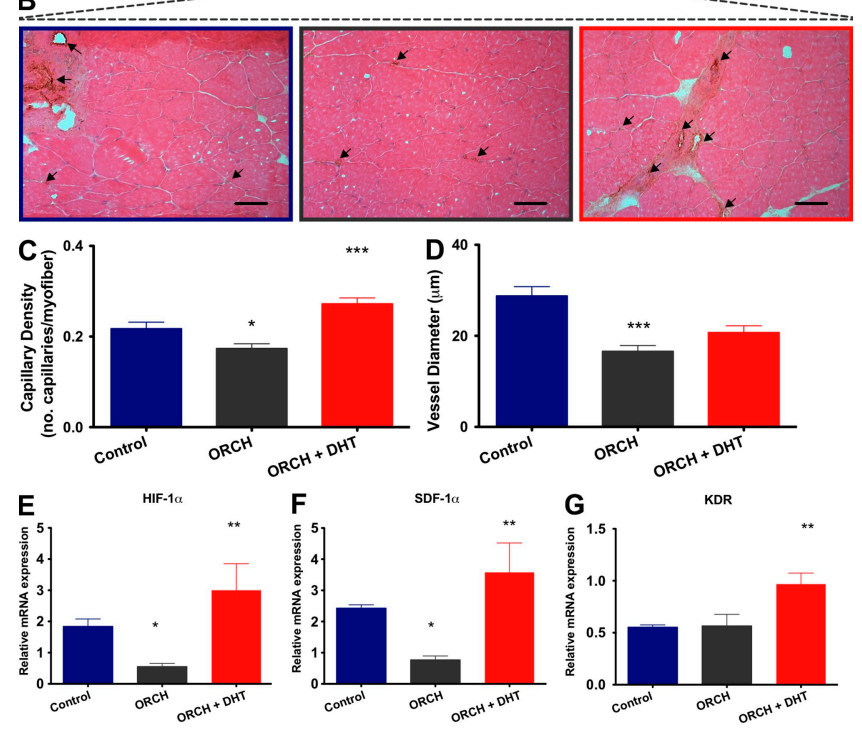

Figure 5. Endogenous androgens modulate ischemia-induced angiogenesis. (A) LDPI. Limb perfusion ratio (ischemic/nonischemic) is presented with representative images ( $n=8 /$ group; combined data from four independent experiments are shown). Differences between groups were assessed by two-way ANOVA with Bonferroni correction (brackets at right). ${ }^{*}, \mathrm{P}<0.05$; and ${ }^{*}, \mathrm{P}<0.01$ for comparisons between orchidectomized and orchidectomized + DHT mice at individual time points. (B) Representative images of neovascularization of ischemic hindlimbs at day 7 . Capillary density was measured in 8- $\mu \mathrm{m}$ frozen sections of the adductor muscles via immunohistochemical staining for vWF (arrows). Bars, $100 \mu \mathrm{m}$. (C) Capillary density expressed as the number of capillaries per myofiber (eosin) and (D) mean vessel diameter ( $n=6 /$ group; combined data from three independent experiments are shown). (E-G) Mechanisms of androgenic modulation of angiogenesis in hindlimb ischemia at day 3. Quantitative RT-PCR for the expression of the angiogenesis- and ischemia-related genes (E) HIF- $1 \alpha$, (F) SDF- $1 \alpha$, and (G) KDR ( $n=6 /$ group; combined data from three independent experiments are shown). ${ }^{*}, \mathrm{P}<0.05 ;{ }^{*}, \mathrm{P}<0.01$; and ${ }^{* * *}, P<0.001$ versus control using ANOVA. All data are expressed as means \pm SEM. 
VEGF in this context. Overall, these findings suggest that endogenous androgens play a role in the coordination of ischemia-mediated angiogenesis by the regulation of key angiogenesis-related genes, including HIF- $1 \alpha$ and SDF- $1 \alpha$.

\section{Androgens modulate ischemia-induced angiogenic/progenitor cell mobilization}

It is now clear that the mobilization of various angiogenic/ progenitor cells from the bone marrow to sites of ischemia is critical for neovascularization (Sieveking and Ng, 2009). Because the spleen serves as a reservoir for peripheral stem/progenitor cells (Heeschen et al., 2003), to further elucidate the mechanisms of androgen-induced angiogenesis in hindlimb ischemia, the early mobilization of angiogenic/progenitor cells was assessed in both the bone marrow and the spleen. Mononuclear cells (MNCs) staining positive for ulex lectin and uptake of Dilacetylated low density lipoprotein (AcLDL) represent a heterogeneous population of cells with angiogenic activity (Asahara et al., 1997). Although the precise role of these cells in angiogenesis has been debated, these cells have been reported to augment angiogenesis in a paracrine fashion through the secretion of various growth factors (Heil et al., 2004; Sieveking et al., 2008). In females, estrogen has also been demonstrated to mobilize bone marrow-derived angiogenic/progenitor cells that participate in cardiovascular regeneration (Iwakura et al., 2006). Similarly, the findings of this study show that androgens modulate the mobilization of angiogenic cells. Orchidectomy markedly decreased the numbers of $u$ lex $x^{+} / \mathrm{AcLDL}^{+}$cells in the bone marrow $(22.8 \pm 1$ vs. $13.4 \pm 0.9$ cells $/ 200 \times$ field for control vs. orchidectomized mice, respectively; $\mathrm{P}<0.001$ using ANOVA; Fig. $6 \mathrm{~A})$ and the spleen $(20.6 \pm 0.8$ vs. $15.2 \pm 0.7$ cells $/ 200 \times$ field for control vs. orchidectomized mice, respectively; $\mathrm{P}<$ 0.001 using ANOVA; Fig. 6 B). DHT treatment rescued castration-mediated decline in $u l e x^{+} / \mathrm{AcLDL}^{+}$angiogenic cells in both the spleen $(17.8 \pm 0.9$ cells $/ 200 \times$ field; $\mathrm{P}>0.05$ using ANOVA) and the bone marrow (31.7 \pm 5 cells $/ 200 \times$ field; $\mathrm{P}<0.001$ using ANOVA). SDF-1 $\alpha$ is a key chemokine in the migration and homing of bone marrow-derived progenitor cells to sites of ischemia, and is itself a ligand for the receptor CXCR 4 (Jin et al., 2006); therefore, we also assessed the levels of $\mathrm{CXCR} 4^{+} / \mathrm{Sca}-1^{+}$progenitor cells after induction of hindlimb ischemia. Consistent with increased expression of SDF-1 $\alpha$, orchidectomized mice receiving DHT had significantly elevated numbers of $\mathrm{CXCR} 4^{+} / \mathrm{Sca}-1^{+}$cells present in the bone marrow at day 3 after ischemia $(0.8 \pm 0.2 \%$ vs. $0.4 \pm 0.07 \%$ of MNCs for orchidectomized + DHT vs. controls, respectively; $\mathrm{P}<0.05$ using ANOVA; Fig. $6 \mathrm{C}$ ). Trends similar to those seen for $u l e x^{+} / \mathrm{AcLDL}^{+}$cells were observed in the spleen for $\mathrm{CXCR} 4^{+} / \mathrm{Sca}-1^{+}$cells (i.e., decrease with castration and increase with DHT treatment), but these were not statistically significant (Fig. 6 D). The mobilization of cells from the bone marrow to the periphery is a highly coordinated, time-dependent event. Therefore, because sampling took place at day 3 , it is possible that the significantly elevated numbers of $\mathrm{Sca}-1^{+} /$ CXCR $4^{+}$cells in the bone marrow would not correspond to higher levels in the periphery until a later time point. Overall, our findings suggest that androgens play a role in the proliferation and mobilization of circulating angiogenic cell populations in the context of ischemia.

Finally, in light of the well-established effects of androgens on erythropoiesis (Kennedy and Gilbertsen, 1957), we assessed erythroid progenitor cell levels, as these cells have been demonstrated to augment angiogenesis (Sasaki et al., 2007). Gonadal status had no effect on the numbers of granulocyte/macrophage progenitors present in the bone marrow or the spleen (Fig. 6, E and F). However, consistent
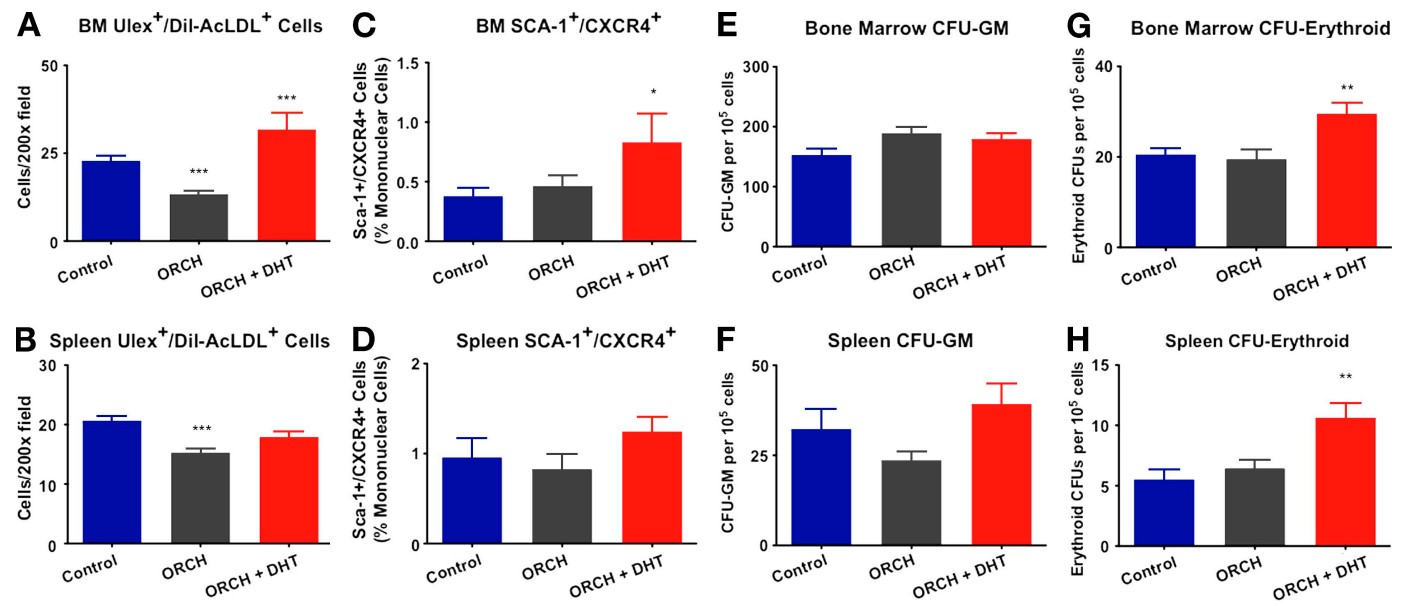

Figure 6. Endogenous androgens modulate angiogenic/progenitor cell mobilization in response to ischemia. (A and $B) U / e x^{+} / A c L D L^{+}$cells in the bone marrow (A) and spleen (B). Cells were seeded at a density of $5 \times 10^{6} \mathrm{cells} / \mathrm{mm}^{2}$ and after $4 \mathrm{~d}$ were assessed for the ability to ingest $4 \mu \mathrm{g} / \mathrm{ml} \mathrm{AcLDL}$ (Invitrogen) and to bind $10 \mathrm{\mu g} / \mathrm{ml}$ FITC-UEA-1 (Sigma-Aldrich) via fluorescence microscopy. (C and D) SCA-1+/CXCR4+ cells in the bone marrow (C) and spleen (D). Hematopoietic progenitor cells were assessed using methylcellulose assays. (E and F) Granulocyte/macrophage CFUs in the bone marrow $(\mathrm{E})$ and spleen $(\mathrm{F})$. ( $\mathrm{G}$ and $\mathrm{H})$ Erythroid CFUs in the bone marrow $(\mathrm{G})$ and spleen $(\mathrm{H} ; n=6 /$ group; combined data from three independent experiments are shown). ${ }^{*}, \mathrm{P}<0.05 ;{ }^{* *}, \mathrm{P}<0.01$; and ${ }^{* *}, \mathrm{P}<0.001$ using ANOVA. All data are expressed as means $\pm \mathrm{SEM}$. 
with the enhanced recovery from ischemia observed in orchidectomized mice treated with DHT, erythroid progenitors were significantly elevated in these mice in both the bone marrow ( $29.5 \pm 2$ vs. $20.5 \pm 1$ erythroid CFUs $/ 10^{5}$ MNCs for orchidectomized + DHT vs. control, respectively; P < 0.01 using ANOVA; Fig. $6 \mathrm{G}$ ) and the spleen (10.6 \pm 1 vs. $5.5 \pm 1$ erythroid CFUs $/ 10^{5}$ MNCs for orchidectomized + DHT vs. control, respectively; $\mathrm{P}<0.01$ using ANOVA; Fig. $6 \mathrm{H}$ ). These data suggest that the enhanced recovery from hindlimb ischemia seen in orchidectomized males receiving DHT may be mediated in part by increased mobilization of erythroid progenitors. In toto, the data presented in this report suggest that endogenous androgens are necessary in the coordination of neovascularization in response to critical ischemia and that consequent proangiogenic effects of DHT in this context are mediated in part through increased angiogenic/progenitor cell mobilization.

In summary, we report a sex-specific role for androgens in angiogenesis. Androgens stimulate key angiogenic events in male but not female cells in vitro, and these sex-specific proangiogenic effects are mediated via the AR. In addition, we report that endogenous androgens modulate angiogenesis in males but not females in vivo. Moreover, in males, endogenous androgens are involved in the coordination and enhancement of neovascularization in the context of ischemic injury. Our findings suggest that androgens regulate vascular regeneration in a sex-dependent manner. Given the agerelated decline of androgens, our findings have implications for the role of androgen replacement in men. Additionally, these data may explain in part some of the observed sex differences in the outcomes of CVD.

\section{MATERIALS AND METHODS}

Cell culture. Human umbilical vein ECs (HUVECs), freshly isolated as described previously (Sieveking et al., 2008), were used in this study as they are well validated in the study of angiogenesis and enabled the assessment of a variety of male and female donors by primary cell harvest and culture. The sex of HUVECs derived from male and female newborns was confirmed via PCR analysis of the X-Y amelogenin gene (Akane, 1998). Cells (passages 2-4) were grown in phenol red-free endothelial growth medium supplemented with FBS that was stripped of endogenous steroids by $2 \%$ charcoal-dextran treatment. Cells were treated with the nonaromatizable androgen DHT $(0$, $4,40$, or $400 \mathrm{nM})$ with and without the AR antagonist $\mathrm{HF}(40 \mu \mathrm{M})$, and assayed for migration, proliferation, and vascular network formation as previously described (Sieveking et al., 2008), and a traditional Matrigel assay. Umbilical cords were obtained under ethical approvals of the Sydney South West Area Health Service Human Ethics Committee.

AR silencing/overexpression. AR silencing was assessed using a commercially available plasmid containing an oligonucleotide encoding an AR siRNA (pKD-AR-v2; Millipore). To increase AR expression in female cells, we used an AR expression plasmid (pSVARo; provided by A.O. Brinkmann, Erasmus University Rotterdam, Rotterdam, Netherlands).

DHT and VEGF signaling in male ECs. After exposure to DHT for $48 \mathrm{~h}$, cell lysates were assayed via ELISA (R\&D Systems). Additionally, the effect of DHT on male EC tubulogenesis was assessed in the presence of $1 \mu \mathrm{g} /$ $\mathrm{ml}$ anti-VEGF antibody (R\&D Systems) or $10 \mu \mathrm{M}$ LY294002 (Merck), an inhibitor of PI3K. Expression of Flt-1 and KDR was assessed via flow cytometry using PE-conjugated antibodies against each antigen (R\&D Systems).
Real-time RT-PCR. Real-time RT-PCR was performed in triplicate using iQ SYBR Green Supermix and the iCycler Real-Time PCR Detection System (Bio-Rad Laboratories). For the animal studies, the relative expression (R) of each target mRNA was calculated based on the Pfaffl equation (Pfaffl, 2001), as follows: $\mathrm{R}=\left(\mathrm{E}_{\text {target }}\right)^{\Delta \mathrm{Ct} \text { target }} /\left(\mathrm{E}_{\text {reference }}\right)^{\Delta \mathrm{Ctreference}}$, where $\Delta \mathrm{Ct}=\mathrm{Ct}_{\text {ischemic }}-$ $\mathrm{Ct}_{\text {nonischemic. }}$. The reference was $\beta$-actin or $\beta 2$-microglobuin mRNA.

Animal studies. All animal studies were performed under ethical approvals of the Sydney South West Area Health Service Animal Welfare Committee. Male and female C57B16/J mice at $6 \mathrm{wk}$ of age were randomized to orchidectomy, ovariectomy, or sham castration. $10 \mathrm{~d}$ later, castrated mice received a $1-\mathrm{cm}$ subdermal silastic implant filled with crystalline DHT.

Matrigel plug implantation model. Matrigel plug assays were performed as described previously (Passaniti et al., 1992). Commercially available Matrigel (BD) without phenol red was supplemented with $100 \mathrm{ng} / \mathrm{ml}$ of basic fibroblast growth factor.

Hindlimb ischemia model. Hindlimb ischemia and subsequent perfusion (Moor Instruments) and monitoring was performed as described previously (Stabile et al., 2003).

Angiogenic/progenitor cell mobilization. For flow cytometric analysis (FC500; Beckman Coulter), MNCs were stained with PE-conjugated antibodies against SCA-1 (BioLegend) and FITC-conjugated antibodies against CXCR 4 (BD) with matched isotype controls. CFU assays for granulocyte/ macrophage and erythroid progenitors were set up in methylcellulose medium (MethoCult; STEMCELL Technologies Inc.).

Statistical analysis. Data are expressed as means \pm SEM. Comparisons between groups were performed using a two-tailed $t$ test or by a one-way ANOVA with post hoc analyses for pairwise comparisons (Newman-Keuls multiple comparison). Prism software (version 4.00; GraphPad Software, Inc.) for Windows was used for statistical analysis.

Online supplemental material. Fig. S1 depicts a dose-dependent augmentation of Matrigel-based tubulogenesis in male ECs exposed to DHT for $24 \mathrm{~h}$. In Fig. S2, we show differential gene expression of the AR in male and female ECs as well as female ECs transfected with an AR expression vector. Fig. S3 demonstrates the effect of castration and DHT treatment on the functional recovery of male mice subjected to femoral artery ligation. Fig. S4 shows the expression of angiogenesis-related genes in response to hindlimb ischemia. Online supplemental material is available at http://www.jem .org/cgi/content/full/jem.20091924/DC1.

We wish to thank Professor R.H. Karas for providing scientific advice during the preparation of this paper.

This study was supported by a grant from the National Health and Medical Research Council (457534). D.P. Sieveking was supported by a postgraduate support grant from GlaxoSmithKline Australia.

The authors have no conflicting financial interests.

Submitted: 3 September 2009 Accepted: 21 December 2009

\section{REFERENCES}

Abaci, A., A. Oğuzhan, S. Kahraman, N.K. Eryol, S. Unal, H. Arinç, and A. Ergin. 1999. Effect of diabetes mellitus on formation of coronary collateral vessels. Circulation. 99:2239-2242.

Akane, A. 1998. Sex determination by PCR analysis of the X-Y amelogenin gene. Methods Mol. Biol. 98:245-249.

Araujo, A.B., V. Kupelian, S.T. Page, D.J. Handelsman, W.J. Bremner, and J.B. McKinlay. 2007. Sex steroids and all-cause and cause-specific mortality in men. Arch. Intern. Med. 167:1252-1260. doi:10.1001/ archinte.167.12.1252 
Asahara, T., T. Murohara, A. Sullivan, M. Silver, R. van der Zee, T. Li, B. Witzenbichler, G. Schatteman, and J.M. Isner. 1997. Isolation of putative progenitor endothelial cells for angiogenesis. Science. 275:964-967. doi:10.1126/science. 275.5302 .964

Boddy, J.L., S.B. Fox, C. Han, L. Campo, H. Turley, S. Kanga, P.R. Malone, and A.L. Harris. 2005. The androgen receptor is significantly associated with vascular endothelial growth factor and hypoxia sensing via hypoxia-inducible factors HIF-1a, HIF-2a, and the prolyl hydroxylases in human prostate cancer. Clin. Cancer Res. 11:7658-7663. doi:10.1158/1078-0432.CCR-05-0460

Carmeliet, P. 2005. Angiogenesis in life, disease and medicine. Nature. 438:932-936. doi:10.1038/nature04478

Ceradini, D.J., and G.C. Gurtner. 2005. Homing to hypoxia: HIF-1 as a mediator of progenitor cell recruitment to injured tissue. Trends Cardiovasc. Med. 15:57-63. doi:10.1016/j.tcm.2005.02.002

Ceradini, D.J., A.R. Kulkarni, M.J. Callaghan, O.M. Tepper, N. Bastidas, M.E. Kleinman, J.M. Capla, R.D. Galiano, J.P. Levine, and G.C. Gurtner. 2004. Progenitor cell trafficking is regulated by hypoxic gradients through HIF-1 induction of SDF-1. Nat. Med. 10:858-864. doi:10.1038/nm1075

Couffinhal, T., M. Silver, L.P. Zheng, M. Kearney, B. Witzenbichler, and J.M. Isner. 1998. Mouse model of angiogenesis. Am. J. Pathol. 152:1667-1679.

Death, A.K., K.C. McGrath, M.A. Sader, S. Nakhla, W. Jessup, D.J. Handelsman, and D.S. Celermajer. 2004. Dihydrotestosterone promotes vascular cell adhesion molecule-1 expression in male human endothelial cells via a nuclear factor-kappaB-dependent pathway. Endocrinology. 145:1889-1897. doi:10.1210/en.2003-0789

Ferrara, N., H.P. Gerber, and J. LeCouter. 2003. The biology of VEGF and its receptors. Nat. Med. 9:669-676. doi:10.1038/nm0603-669

Harman, S.M. 2005. Testosterone in older men after the Institute of Medicine Report: where do we go from here? Climacteric. 8:124-135. doi:10.1080/13697130500042417

Heeschen, C., A. Aicher, R. Lehmann, S. Fichtlscherer, M. Vasa, C. Urbich, C. Mildner-Rihm, H. Martin, A.M. Zeiher, and S. Dimmeler. 2003. Erythropoietin is a potent physiologic stimulus for endothelial progenitor cell mobilization. Blood. 102:1340-1346. doi:10.1182/blood-2003-01-0223

Heil, M., T. Ziegelhoeffer, B. Mees, and W. Schaper. 2004. A different outlook on the role of bone marrow stem cells in vascular growth: bone marrow delivers software not hardware. Circ. Res. 94:573-574. doi:10.1161/01.RES.0000124603.46777.EB

Iwakura, A., S. Shastry, C. Luedemann, H. Hamada, A. Kawamoto, R. Kishore, Y. Zhu, G. Qin, M. Silver, T. Thorne, et al. 2006. Estradiol enhances recovery after myocardial infarction by augmenting incorporation of bone marrow-derived endothelial progenitor cells into sites of ischemia-induced neovascularization via endothelial nitric oxide synthase-mediated activation of matrix metalloproteinase-9. Circulation. 113:1605-1614. doi:10.1161/CIRCULATIONAHA.105.553925

Jin, D.K., K. Shido, H.G. Kopp, I. Petit, S.V. Shmelkov, L.M. Young, A.T. Hooper, H. Amano, S.T. Avecilla, B. Heissig, et al. 2006. Cytokinemediated deployment of SDF-1 induces revascularization through recruitment of CXCR4+ hemangiocytes. Nat. Med. 12:557-567. doi: $10.1038 / \mathrm{nm} 1400$

Joseph, J., and M. Dyson. 1965. Sex differences in the rate of tissue regeneration in the rabbit's ear. Nature. 208:599-600. doi:10.1038/208599a0

Kennedy, B.J., and A.S. Gilbertsen. 1957. Increased erythropoiesis induced by androgenic-hormone therapy. N. Engl. J. Med. 256:719-726.

Khaw, K.T., M. Dowsett, E. Folkerd, S. Bingham, N. Wareham, R. Luben, A. Welch, and N. Day. 2007. Endogenous testosterone and mortality due to all causes, cardiovascular disease, and cancer in men: European prospective investigation into cancer in Norfolk (EPICNorfolk) Prospective Population Study. Circulation. 116:2694-2701. doi:10.1161/CIRCULATIONAHA.107.719005

Laughlin, G.A., E. Barrett-Connor, and J. Bergstrom. 2008. Low serum testosterone and mortality in older men. J. Clin. Endocrinol. Metab. 93:68-75. doi:10.1210/jc.2007-1792

Liu, P.Y., A.K. Death, and D.J. Handelsman. 2003. Androgens and cardiovascular disease. Endocr. Rev. 24:313-340. doi:10.1210/er.2003-0005
Losordo, D.W., and J.M. Isner. 2001. Estrogen and angiogenesis: A review. Atterioscler. Thromb. Vasc. Biol. 21:6-12.

McCrohon, J.A., W. Jessup, D.J. Handelsman, and D.S. Celermajer. 1999 Androgen exposure increases human monocyte adhesion to vascular endothelium and endothelial cell expression of vascular cell adhesion molecule-1. Circulation. 99:2317-2322.

McCrohon, J.A., A.K. Death, S. Nakhla, W. Jessup, D.J. Handelsman, K.K. Stanley, and D.S. Celermajer. 2000. Androgen receptor expression is greater in macrophages from male than from female donors. A sex difference with implications for atherogenesis. Circulation. 101:224-226.

Morales, D.E., K.A. McGowan, D.S. Grant, S. Maheshwari, D. Bhartiya, M.C. Cid, H.K. Kleinman, and H.W. Schnaper. 1995. Estrogen promotes angiogenic activity in human umbilical vein endothelial cells in vitro and in a murine model. Circulation. 91:755-763.

Ng, M.K., W. Jessup, and D.S. Celermajer. 2001. Sex-related differences in the regulation of macrophage cholesterol metabolism. Curr. Opin. Lipidol. 12:505-510. doi:10.1097/00041433-200110000-00005

Ng, M.K., S. Nakhla, A. Baoutina, W. Jessup, D.J. Handelsman, and D.S. Celermajer. 2003a. Dehydroepiandrosterone, an adrenal androgen, increases human foam cell formation: a potentially pro-atherogenic effect. J. Am. Coll. Cardiol. 42:1967-1974. doi:10.1016/j.jacc.2003.07.024

Ng, M.K., C.M. Quinn, J.A. McCrohon, S. Nakhla, W. Jessup, D.J. Handelsman, D.S. Celermajer, and A.K. Death. 2003b. Androgens upregulate atherosclerosis-related genes in macrophages from males but not females: molecular insights into gender differences in atherosclerosis. J. Am. Coll. Cardiol. 42:1306-1313. doi:10.1016/j.jacc.2003.07.002

Passaniti, A., R.M. Taylor, R. Pili, Y. Guo, P.V. Long, J.A. Haney, R.R. Pauly, D.S. Grant, and G.R. Martin. 1992. A simple, quantitative method for assessing angiogenesis and antiangiogenic agents using reconstituted basement membrane, heparin, and fibroblast growth factor. Lab. Invest. 67:519-528.

Pfaff, M.W. 2001. A new mathematical model for relative quantification in real-time RT-PCR. Nucleic Acids Res. 29:e45. doi:10.1093/ nar/29.9.e45

Sasaki, S., T. Inoguchi, K. Muta, Y. Abe, M. Zhang, K. Hiasa, K. Egashira, N. Sonoda, K. Kobayashi, R. Takayanagi, and H. Nawata. 2007. Therapeutic angiogenesis by ex vivo expanded erythroid progenitor cells. Am. J. Physiol. Heart Circ. Physiol. 292:H657-H665 doi:10.1152/ajpheart.00343.2006

Semenza, G.L. 2002. HIF-1 and tumor progression: pathophysiology and therapeutics. Trends Mol. Med. 8(Suppl.):S62-S67. doi:10.1016/S1471-4914(02)02317-1

Shaw, L.J., C.N. Bairey Merz, C.J. Pepine, S.E. Reis, V. Bittner, S.F. Kelsey, M. Olson, B.D. Johnson, S. Mankad, B.L. Sharaf, et al; WISE Investigators. 2006. Insights from the NHLBI-sponsored Women's Ischemia Syndrome Evaluation (WISE) study: Part I: gender differences in traditional and novel risk factors, symptom evaluation, and genderoptimized diagnostic strategies. J. Am. Coll. Cardiol. 47(Suppl. 1):S4S20. doi:10.1016/j.jacc.2005.01.072

Sieveking, D.P., and M.K. Ng. 2009. Cell therapies for therapeutic angiogenesis: back to the bench. Vasc. Med. 14:153-166. doi:10.1177/ 1358863X08098698

Sieveking, D.P., A. Buckle, D.S. Celermajer, and M.K. Ng. 2008. Strikingly different angiogenic properties of endothelial progenitor cell subpopulations: insights from a novel human angiogenesis assay. J. Am. Coll. Cardiol. 51:660-668. doi:10.1016/j.jacc.2007.09.059

Stabile, E., M.S. Burnett, C. Watkins, T. Kinnaird, A. Bachis, A. la Sala, J.M. Miller, M. Shou, S.E. Epstein, and S. Fuchs. 2003. Impaired arteriogenic response to acute hindlimb ischemia in CD4-knockout mice. Circulation. 108:205-210. doi:10.1161/01.CIR.0000079225.50817.71

Tivesten, A., L. Vandenput, F. Labrie, M.K. Karlsson, O. Ljunggren, D. Mellström, and C. Ohlsson. 2009. Low serum testosterone and estradiol predict mortality in elderly men. J. Clin. Endocrinol. Metab. 94:2482-2488.

Wingard, D.L., L. Suarez, and E. Barrett-Connor. 1983. The sex differential in mortality from all causes and ischemic heart disease. Am. J. Epidemiol. 117:165-172.

Wu, F.C., and A. von Eckardstein. 2003. Androgens and coronary artery disease. Endocr. Rev. 24:183-217. doi:10.1210/er.2001-0025 